\title{
DIAMONDIFEROUS ECLOGITE DISSECTIONS: ANOMALOUS DIAMOND GENESIS?
}

\author{
Mahesh Anand* ${ }^{1}$, Lawrence A. Taylor ${ }^{1}$, Kula C. Misra ${ }^{1}$, William D. Carlson ${ }^{2}$ and Nikolai V. \\ Sobolev ${ }^{3}$ \\ ${ }^{1}$ Planetary Geosciences Institute, Department of Geological Sciences, University of Tennessee, Knoxville, TN 37996, USA \\ ${ }^{2}$ Department of Geological Sciences, University of Texas, Austin, TX 78712, USA \\ ${ }^{3}$ Institute of Mineralogy \& Petrography, Russian Academy of Sciences, Novosibirsk 630090, Russia
}

\section{INTRODUCTION}

Almost all diamonds occur in kimberlites as loose crystals, being liberated from their mantle host rocks during the transport to the Earth's surface. In some instances, however, diamonds are recovered directly from their mantle hosts, such as peridotite and eclogite xenoliths. However, due to the friable nature of peridotites, during their transport in the kimberlitic magma, they are mostly all disaggregated and their diamonds are released into the kimberlite. In contrast, due to greater resistance, eclogite xenoliths sometimes remain intact, thereby preserving the textural context in which their diamonds originally formed. Studies of these diamondiferous mantle xenoliths provide us a unique opportunity to understand the textural and spatial relationships between diamonds and their host mineralogy. In an endeavor to further understand the importance of diamonds and their DIs in relation to their host rocks, we have investigated several diamondiferous eclogites from Yakutian kimberlites, first by High Resolution Xray Computed Tomography (HRXCT) (Anand et al., this volume), and then by dissection of the eclogites into their individual minerals. Subsequently, we have performed an extensive set of mineralogical, chemical, and isotopic measurements on the host eclogite minerals, on the diamonds and their inclusions. In addition, we have also performed cathodoluminescence studies of polished diamond surfaces, which highlight the complicated growth histories that these diamonds have experienced.

\section{ECLOGITE DISSECTION}

All of the xenoliths studied are highly diamondiferous (e.g., one $66 \mathrm{~g}$ eclogite contains 74 macro diamonds [> $1 \mathrm{~mm}$ ], equivalent to 144,000 carat/ton). In Yakutia, during the processing of the kimberlite, the ore is crushed to $\sim 5-6 \mathrm{~cm}$ size, washed, and passed along a conveyor belt. These golf-ball-sized rocks are exposed to X-rays, whereby any diamonds exposed at their surface will fluoresce a bright blue. Sensed by a detector, a shot of compressed air moves the rock off the belt into a rubber bag. This diamondiferous sample is handled carefully so as to recover the possibly large diamonds. The diamondiferous eclogites that our group has been studying for several years are from these suites of scientifically invaluable samples. One such xenolith (UX-1) showing a diamond exposed on its surface is shown in Fig. 1. There were more than 5 diamonds exposed on the surface of this xenolith that were carefully removed during our detailed dissection; another 69 diamonds were inside.

We have used high-resolution tomography to image minerals, including the diamonds, in the eclogites. This is a novel technique, which uses similar principles to that of medical CAT-scan, in which a series of 2-D Xray slices are obtained by passing X-rays through a sample (Rowe et al., 1997). The advantage of this technique over conventional CAT-scan is the higher inplane resolution (normally $\sim 10-20 \mu \mathrm{m}$ ). This is the first time that such a method has been used to investigate the

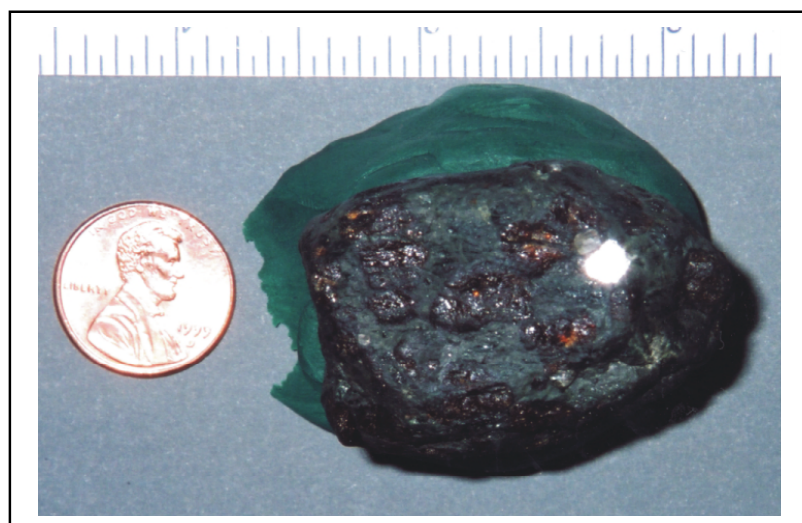

Figure 1: Eclogite xenolith (UX-1) from Udachnaya kimberlite pipe, Yakutia. This eclogite is exceptionally rich in diamonds. One such macro-diamond is seen exposed on the surface of the xenolith. Reddishbrown garnets are clearly seen with interstitial bottle green clinopyroxenes. The green mass in the background is silicon putty, used to stabilize the sample. 


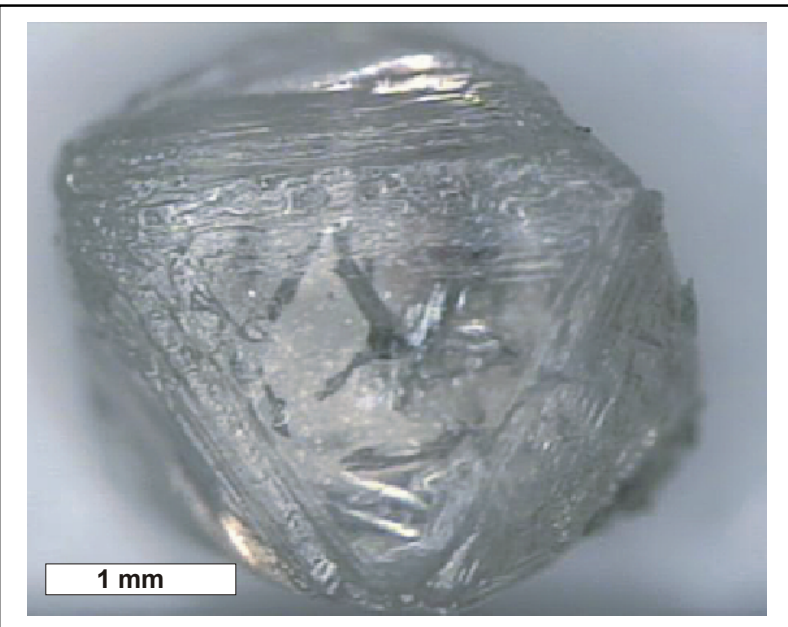

Figure 2: Photograph of a diamond recovered during eclogite dissection of UX-1. An octahedral face of the diamond is seen facing the page. Dark elongated inclusions of sulfides are also seen in the middle of the octahedral face of the diamond.

orientations and distribution of diamonds in an eclogite xenolith. Based on these HRXCT images, we have dissected diamondiferous eclogites along selected planes such that the diamonds could be extracted with minimum loss of surrounding materials. The nature and physical properties of minerals, in direct contact with diamonds are especially noted at the time of diamond extraction. Subsequently, polished thin sections of the eclogites were made, containing the mold areas of the diamonds, to further investigate the mineralogy and chemistry of the host minerals that were in contact with diamonds.

The majority of the extracted diamonds occur as perfect octahedra, others as cubo-octahedra, with welldeveloped crystal faces (Fig. 2); some also occur as macles (twins). In one instance, a cluster of diamonds, weighing over $3 / 4$ carat, was recovered, but due to polycrystalline nature of this cluster, it was not possible to separate individual diamonds. The color of the recovered diamonds varies from colorless to yellowish white. The size and weight of the diamonds vary from less than 1 to $4 \mathrm{~mm}$ and 0.03 to 1 carat, respectively.

The systematic eclogite dissections have revealed that the diamonds are invariably associated with clinopyroxenes, being only separated by a narrow alteration zone. Fresh clinopyroxene and garnet were never found in direct contact with diamond. It is not clear if this spatial relationship of diamond and clinopyroxene alteration zones have any specific genetic significance. However, it does appear as if the diamond-precipitating fluid has selectively invaded the clinopyroxene grain boundaries. Alternatively, the diamond-clinopyroxene interface might have provided an increased permeability contrast thereby promoting late-stage alteration in the host xenolith. Figure 3 shows a back-scatterelectron (BSE) image of a section of the eclogite, which contains the contact between diamond and clinopyroxene in the host rock. Closer inspection of Figure 3 indi-

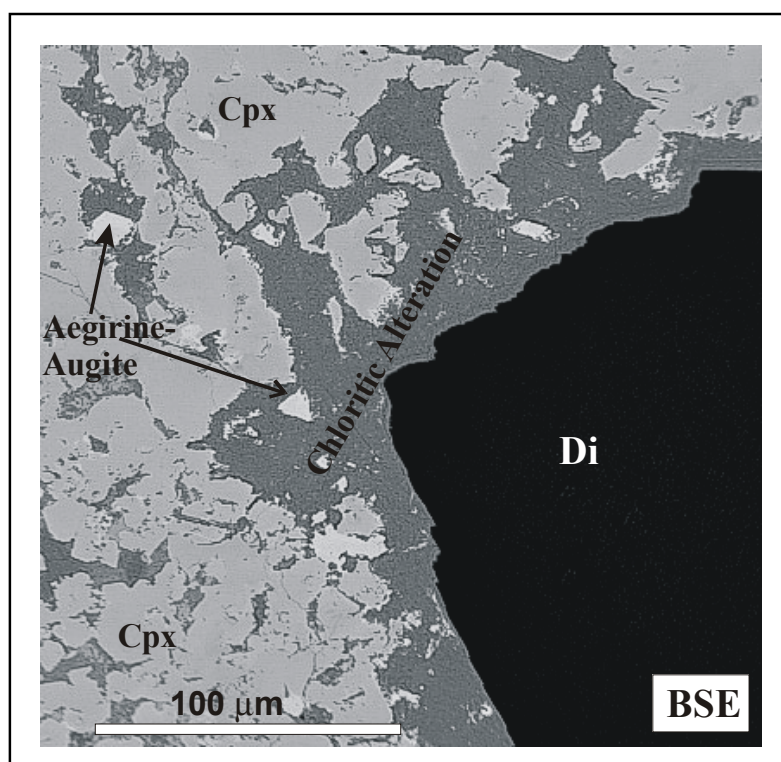

Figure 3: BSE image of a dissected eclogite section showing the contact between the diamond and host mineral. In the present case, the original clinopyroxene in contact with the diamond has been replaced by chloritic alteration. Note that the large black space on the photograph represents the mold of the diamond, which has been removed.

cates that diamond-silicate contact is very sharp, but it has negative diamond morphology, suggesting that the alteration is definitely post-diamond formation. Another noticeable feature of this figure is the presence of islands of aegirine-augite in the alteration patches. This further suggests that the alteration took place at relatively elevated oxygen fugacity, such that $\mathrm{Fe}^{3+}$ in the pyroxene was also stable. Other phases are also present in the alteration assemblage, as described in Spetsius and Taylor (2002) and Misra et al. (2003).

\section{HOST MINERALOGY}

The eclogites are Group B and C types, consisting of primary garnet that is typically almandine and grossular rich, omphacitic pyroxene with $6-10 \mathrm{wt} \% \mathrm{Na}_{2} \mathrm{O}$, and minor sulfides. No evident chemical zonations were detected in individual grains, and primary Cpxs are 


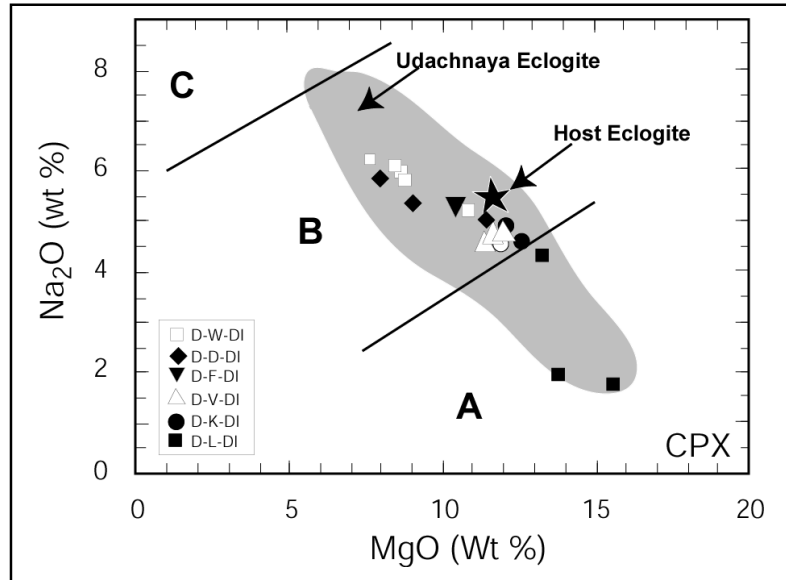

Figure 4: $\mathrm{MgO}$ versus $\mathrm{Na}_{2} \mathrm{O}$ plot for primary $\mathrm{Cpx}$ inclusions in diamonds from eclogite xenolith U51 in comparison with those from the host eclogite and other eclogite xenoliths from the Udachnaya kimberlite pipe (Sobolev et al., 1994). Majority of the DIs, and the host eclogite plot in Group B of Taylor and Neal (1989). Diagram modified after Taylor et al. (2000).

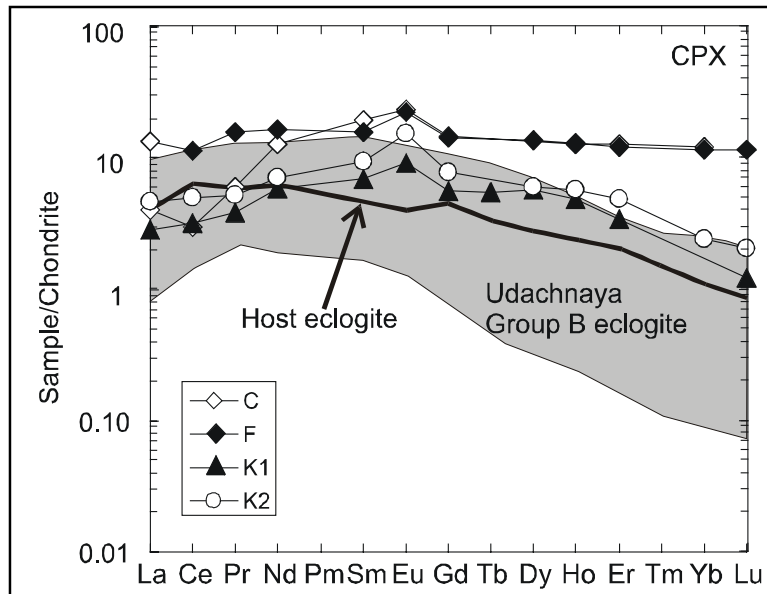

Figure 5: Chondrite-normalized REE patterns of Cpx inclusions from U51 diamonds. These grains were exposed at the diamond surface by polishing, and their compositions were determined in-situ by SIMS. Notice the wide variation in the REE patterns among DIs with respect to the host eclogite. Positive Eu anomalies are clearly evident.

chemically homogeneous throughout the xenolith. The compositions of Cpxs plot within the field of Group B eclogites in the $\mathrm{MgO}$ versus $\mathrm{Na}_{2} \mathrm{O}$ plot (Fig. 4) of Taylor and Neal (1989). Similarly, Gt compositions, within the Ca-Mg-Fe ternary, plot in the Group B eclogite field defined by Coleman et al., (1965). A conspicuous feature of the eclogites is the presence of at least two fluidincursion events that have modified the host eclogite. The earlier of the two was a pervasive $\mathrm{K}$ -

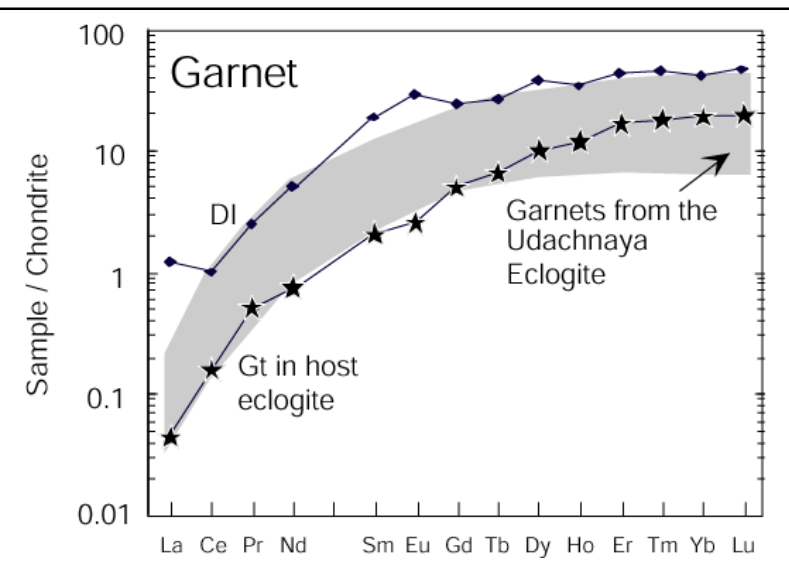

Figure 6: Chondrite-normalized REE pattern for a Gt DI. The host eclogite is depleted in REE's compared to the DI. The DI and the host roughly define the lower and upper limits of the REEs in garnets from Udachnaya eclogites. The DI has a small positive Eu anomaly.

metasomatism, including partial melting, probably under mantle conditions, that converted the omphacite into a distinctive, spongy-textured assemblage, consisting mainly of residual islands of Na-depleted clinopyroxene with 2-3\% less $\mathrm{Na}_{2} \mathrm{O}$, $\mathrm{K}$-enriched glass $\left(\mathrm{K}_{2} \mathrm{O} \sim\right.$ $6 \%, \mathrm{Na}_{2} \mathrm{O} \sim 0.8 \%$ ), and minor amounts of spinel. The colateral alteration of garnet is represented by amphibole-dominated kelyphyte that occurs as rims and thin veins. The altered-pyroxene assemblage is the typical site for the diamonds.

The products of this metasomatic event are superimposed by a later, dominantly chloritic alteration that appears to be preferentially concentrated around sulfide grains and omphacite alteration patches. The sulfide grains are composed of pyrrhotite $(\mathrm{Ni} \sim 0.5 \%)$ close to troilite, exsolved pentlandite ( $\mathrm{Co} \sim 1.5 \%, \mathrm{Cu} \sim 0.2 \%)$, predominantly as oriented lamellar intergrowth, and minor chalcopyrite, most probably present originally as mono sulfide solid solution (Mss). The sulfide assemblages are rimmed by a thin rind of djerfisherite $\left[(\mathrm{K}, \mathrm{Na})_{7}(\mathrm{Fe}, \mathrm{Ni}, \mathrm{Cu})_{24} \mathrm{~S}_{26} \mathrm{Cl}\right]$, an alteration product most likely related to the K-metasomatism, and cut by tentacles of chloritic alteration. The diamond crystals in the xenoliths formed before the chloritic alteration as their contacts are invariably marked by an abrupt termination of a rind of chloritic alteration. The absence of any alteration to the pristine diamond inclusions would seem to indicate that the diamond growth preceded the initial K-metasomatic event (see below). 


\section{DIAMOND INCLUSIONS}

In the diamonds from eclogite xenoliths from Udachnaya, Mss and exsolution products, po + pn + cpy, are the most common DIs, followed by clinopyroxene and garnet. Some Cpx and Gt inclusions were extracted from individual diamonds, whereas some were exposed in-situ on polished diamond surfaces. For in-situ analysis, each diamond was cut and polished along relatively soft directions parallel to either (001) or (110) faces so as to expose DIs. This was followed by detailed examination with CL on an electron micro probe (EMP), to determine the pristinity of the DIs.

Diamond inclusions of both Cpx and Gt are significantly different in chemical composition from those in the host eclogites. This is true both in terms of majorelement, as well as, trace-element compositions (Figs. 4-6). Many of the diamond inclusions from a singleeclogite xenolith show variations in major- and traceelement chemistry. The same is also true for multiple inclusions from a single diamond. Almost all the DIs in the present study show positive Eu anomaly, indicative of their crustal protoliths. These observations further confirm the well-established subduction hypothesis for the origin of Group B eclogites from Udachnaya kimberlite pipe (Snyder et al., 1997). It is also important to note from Figures 4-6 that DI compositions are also different than those of host-eclogite minerals. These observations cast doubt on the usefulness of the host eclogite mineral data as representative of diamondforming medium. Such non-systematic chemical variations among DIs clearly suggest that such inclusions are not co-genetic. Alternatively, these inclusions have somehow been modified by different fluids subsequent to encapsulation. However, no cracks (healed or otherwise) were seen in the cathodoluminescence (CL) study that would support the latter argument. Neverthe- less, there is ample evidence that indeed many of the DIs interact with extraneous fluids via cracks and fractures, after diamond encapsulation. These fractures are optically invisible but when inspected closely by CL, they show evidence for post-diamond formation alteration (see below).

Our CL studies have demonstrated that the many of the diamonds from the studied eclogites have minute, optically invisible cracks (Fig. 7), from the DIs to the surfaces of the diamonds, thereby providing evidence of possible "open system" behavior of the DIs. EMP analyses confirm that some of the DIs were associated with secondary alteration minerals. These minerals are generally located in the cracks, which are only discernible under CL images (Fig. 7). Further CL study showed that the majority of the diamonds have CL zonations recording their severe, often torturous, and contorted, growth histories (Anand et al., 2002). These zones have different $\mathrm{CL}$ colors as a reflection of the different aggregation states and contents of nitrogen within the diamond structure. In addition, the majority of the diamonds show resorption features, due to hiatuses in growth, when the diamonds were partially dissolved back into the fluids from which they may have originally grown. Continued new growth of diamond over these resorbed zones was commonly accompanied by change in growth mode from cubic to octahedral. The outermost portions of many diamonds show weak to no CL, termed "dead zones," and are likely due to metastable diamond growth during tenure in the host kimberlite melt. These observations are consistent with previous suggestions that diamond growth is seldom simple and probably occurs over a significantly long geological time-period and under constantly changing fluid/melt compositions (Taylor et al., 2000).

We have also obtained oxygen isotope data by laser-

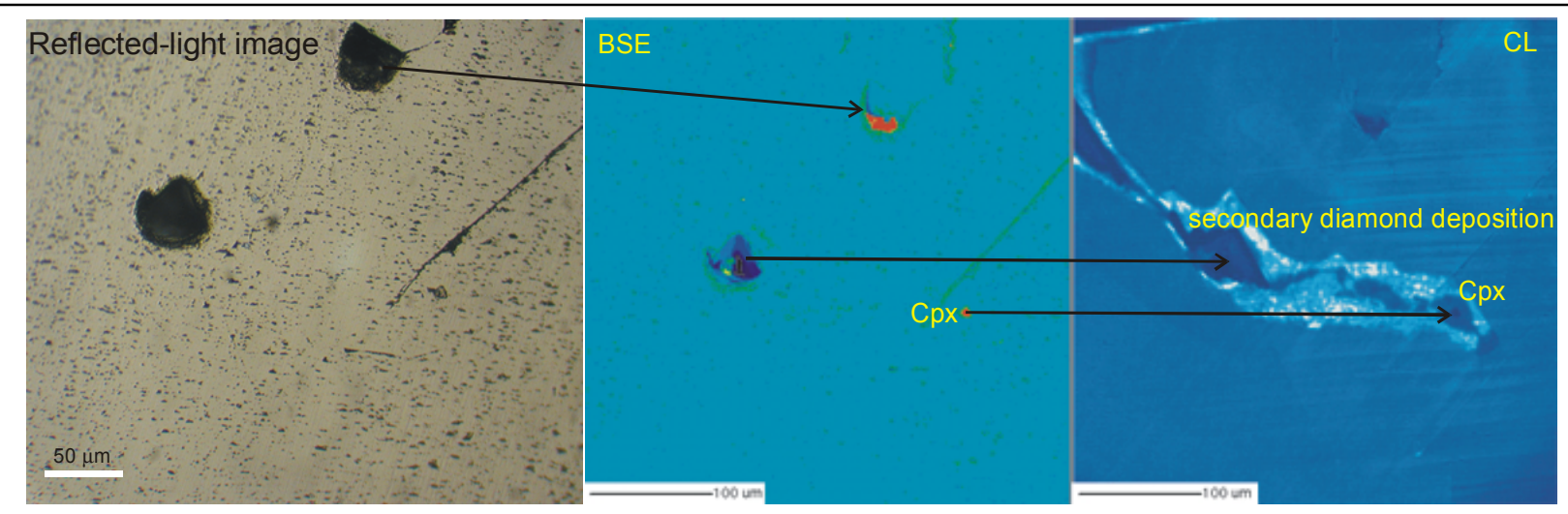

Figure 7: Reflected light, BSE, and CL image of a diamond, recovered from eclogite xenolith, UX1. In RL and BSE, no cracks are visible whereas in CL image, a Cpx inclusion is seen clearly enclosed by a large healed fracture, which extends up to the periphery of the diamond, confirming the open system behavior of the diamond inclusion. 
fluorination technique (Spicuzza et al., 1998) on $5 \mathrm{Cpx}$ and one Gt inclusions in diamonds from U-51 eclogite (Table 1). The overall variation in the Cpx and Gt oxygen isotope data is within the range seen in clinopyroxenes and garnets of Yakutian eclogites (Jacob et al., 1994). However, it is interesting to note that there are significant variations among multiple diamond inclusions from a single diamond (Table 1). This is consistent with our earlier interpretations that mineral inclusions in diamonds from the studied xenoliths suites are widely different in their geochemical characteristics.

\begin{tabular}{|c|c|c|}
\hline Sample No. & $\delta^{18} \mathrm{O}$ (per mil) & $2 \sigma$ \\
\hline W-1 Cpx & 4.4 & 0.9 \\
\hline W-5 Cpx & 2.4 & 1.0 \\
\hline W-14 Cpx & 2.4 & 1.0 \\
\hline V-19 Cpx & 2.9 & 0.8 \\
\hline L-29 Cpx & 4.3 & 0.9 \\
\hline $\mathrm{L}-27 \mathrm{Gt}$ & 8.6 & 1.0 \\
\hline
\end{tabular}

\section{CONCLUSIONS}

Systematic dissections of diamondiferous eclogite xenoliths from Yakutia enabled us to better understand the processes of diamond formation in their eclogite hosts. However, these studies have raised more questions than they have answered. For example, is it an exception rather than a norm that inclusions in diamonds from a single eclogite xenolith show different chemical compositions? More importantly, how typical is it to see chemical variations among multiple inclusions from a single diamond? Is it common for DIs to behave as open systems, such as in the present case? How do diamondiferous eclogite xenoliths from other worldwide localities compare with the Yakutian eclogites in terms of diamond-silicate relationships? Does a diamond precipitate from a melt/fluid or does it form under metamorphic conditions? Such questions can only be answered by an integrated study, of diamonds, diamond inclusions, and their host rocks, such as the one we have just initiated.

It is intuitive to expect that all eclogite xenoliths in a particular kimberlite should have common heritage, at least with respect to their included diamonds. However, the wide variation in the chemistry of multiple DIs within and between diamonds from the same eclogite highlights the anomalous nature of diamond genesis, at least in some of the eclogites from Yakutia.

\section{REFERENCES}

Anand, M., Taylor, L. A., Carlson, W. D., Taylor, D-H., Sobolev, N. V. 2003. Diamond genesis revealed by Xray tomography of diamondiferous eclogites, this meeting.

Anand, M., Taylor, L. A., Carlson, W. D., Taylor, D-H., Sobolev, N. V. 2002. Stratigraphy of diamonds: Complex growth histories highlighted by cathodoluminescence (Abs). AGU Fall Meet. Abs\# V51B-1267.

Coleman, R G., Lee, D. E., Beatty, L. B., Brannock, W. W. 1965. Eclogites and eclogites: Their differences and similarities. Bull. Geol. Soc. Am., 76, 483-508.

Jacob, D., Jagoutz, E., Lowry, D. Mattey, D, and Kudrjavtseva, G., 1994, Diamondiferous eclogites from Siberia: Remanents of Archean oceanic crust. Geochim. Cosmochim. Acta 58, 5191-5207.

Rowe, T., Kappelman, J., Carlson, W. D., Ketcham, R. A., Denison, C. 1997. High-resolution computed tomography: A breakthrough technology for earth scientists. Geotimes, 23-27.

Misra, K. C., Anand, M., Taylor, L. A. 2003. Multistage alteration of (two?) diamondiferous eclogite xenoliths from the Udachnaya kimberlite pipe, Yakutia, Russia. Submitted (Contributions to Mineralogy and Petrology).

Sobolev, V. N., Taylor, L. A., Snyder, G. A., Sobolev, N. V. 1994. Diamondiferous eclogites from the Udachnaya kimberlite pipe, Yakutia. Int. Geol. Rev. 36, 42-64.

Snyder, G. A., Taylor, L. A., Crozaz, G., Halliday, A. N., Beard, B. L., Sobolev, V. N., Sobolev, N. V. 1997. The origins of Yakutian eclogite xenoliths: Jour. Petrol. 38, 85-122.

Spicuzza, M. J., Valley, J. W., Kohn, M. J., Girand, J. P., and Fouillac, A. M., 1998, The rapid heating, defocused beam technique: $\mathrm{A} \mathrm{CO}_{2}$-laser-based method for highly precise and accurate determination of ${ }^{18} \mathrm{O}$ values of quartz. Chem. Geol. 144, 195-203.

Spetsius, Z. V., Taylor, L. A. 2002. Partial melting in mantle eclogite xenoliths: Clues to microdiamond genesis. Int. Geol. Rev. 44, 973-987.

Taylor, L. A., Neal, C R. 1989. Eclogites with oceanic crustal and mantle signatures from the Bellsbank kimberlite, South Africa, Part I: Mineralogy, petrography, and whole-rock chemistry. Jour. Geol. 97, 551-567.

Taylor, L. A., Keller, R. A., Snyder, G. A., Wang, W. Y., Carlson, W. D., Hauri, E. H., McCandless, T., Kim, K. R., Sobolev, N. V. 2000. Diamonds and their mineral inclusions, and what they tell us: A detailed "pullapart" of a diamondiferous eclogite. Int. Geol. Rev. 42, 959-983.

Contact: Mahesh Anand, Planetary Geosciences Institute, Department of Geological Sciences, University of Tennessee, Knoxville, TN-37996, USA, E-mail: anandm@utk.edu 